\title{
The residual stress distribution and fatigue property of TC4 laser-welded joint treated by laser shock peening
}

\author{
Ziwen CAO, Zhigang CHE, Shikun ZOU
}

Science and Technology on Power Beam Processes Laboratory, Beijing Aeronautic Manufacture Technology Research Institute, Beijing, 100024, China

email: svip@163.com

Keywords: Laser Shock Peening; Laser Welding; Compressive Residual Stress; Fatigue Life.

\begin{abstract}
The absence of highly tensile residual stress which distributed in laser welded joint is primary factor of decreasing fatigue life. Laser Shock Peening (LSP) experiments were conducted on TC4 laser welded joints of $2.5 \mathrm{~mm}$ thickness, using circular laser spot with pulse duration of $10 \mathrm{~ns}$, laser power density of $7.2 \mathrm{GW} / \mathrm{cm}^{2}$ and overlapping ratio of $37.5 \%$. Surface residual stress distribution were studied under LSP of one layer, three layers and five layers. Surface tensile residual stresses converted to compressive residual stresses on LSP area, and compressive residual stresses along longitudinal direction were greater than along transverse direction. The amplitude of compressive residual stress were greatly relative to number of LSP layer. Fatigue life of specimens treated by three layers increased $50 \%$ in comparison to untreated specimens (maximum stress:750MPa, stress ratio:0.06). In a word, LSP could adjust residual stress field of laser welded joint, and it is an alternative technology to be potential to substantially improve fatigue performance.
\end{abstract}

\section{Introduction}

Laser welding is widely applied to titanium alloy components in aeronautic manufacturing field, However, Tensile residual stress which distributed near laser welded joint is still studied recently, because it could cause brittle fracture, fatigue fracture and stress corrosion fracture[1] [2]. Due to instantaneous intensive heat input and rapidly cooling during laser welding process, tensile residual stress in laser welded joint is greater than that in other conventional fusion welded joint[3], and it is hardly avoided through optimizing welding parameters. In general, vaccum annealing is primary method to remove tensile residual stress after laser welding, but vaccum annealing could be inapplicability in special conditions, such as limitation of vaccum chamber dimension for large components. Laser shock peening (LSP) is a promising surface strengthening technology. A high pressure plasma explosion induced by intensive laser pulse during LSP produces a plastic deformation to change residual stress distribution on surface, so LSP can be use to mitigate or remove tensile residual stress in welded joint for improve fatigue performance and corrosion resistance[4] [5]. The study of LSP was conducted on TC4 laser welded joints in this paper, to investigated residual stress distribution and fatigue life of laser welded joints.

\section{Laser shock peening experiments}

TC4 ( Ti-6Al-4V) is a two phase $\alpha+\beta$ titanium alloy with chemical composition shown in Table.1. TC4 plates were machined to the dimension of $340 \mathrm{~mm} \times 200 \mathrm{~mm} \times 2.5 \mathrm{~mm}$, and oxide layer of welded plate was removed by etch cleaning before welding. Laser welding (YAG laser power of $2.8 \mathrm{KW}$ and welding velocity of $6 \mathrm{~m} / \mathrm{min}$ ) was carried out at center of plate to simulate butt-weld situation, then laser welded joint surfaces were cleaned by acetone attentively.

Table.1. Chemical compositions of TC4 titanium alloy (wt. \%)

\begin{tabular}{ccccccc}
\hline $\mathrm{Al}$ & $\mathrm{V}$ & $\mathrm{Fe}$ & $\mathrm{C}$ & $\mathrm{N}$ & $\mathrm{O}$ & $\mathrm{Ti}$ \\
\hline $5.5-6.8$ & $3.5-4.5$ & $\leqslant 0.3$ & $\leqslant 0.1$ & $\leqslant 0.05$ & $\leqslant 0.2$ & rest \\
\hline
\end{tabular}


LSP experiments were conducted on laser welded plate keeping reinforcement on joint. Prior to the peening process, laser welded plate was covered by an aluminum tape of $120 \mu \mathrm{m}$ thickness along welded seam, to act as a protective layer against surface burning. Then a confining layer (de-ionized water of approximately $1 \mathrm{~mm}$ thickness) was flowed on laser shock region to restrain plasma overexpansion for enhancing pressure of shock wave. During LSP process, laser beam from Q-switch YAG laser system statically pointed onto laser welded plate, and laser welded plate was driven by robot for moving plate along with a programmed track. Circular laser spots with pulse duration of $10 \mathrm{~ns}$ and laser power density of $7.2 \mathrm{GW} / \mathrm{cm}^{2}$ were shocked on laser welded joint to finish one layer LSP with three rows at overlapping ratio of $37.5 \%$ both between spot to spot and row to row. For multiple layer LSP processing, Each new layer LSP was carried out on unused aluminum tape which repasted after removing the used tape. Surface residual stresses and fatigue property were measured and tested. The fatigue test specimens were cut from titanium alloy plate, and welded seam which located at center normaled to axial direction of specimen as shown in Fig.1.

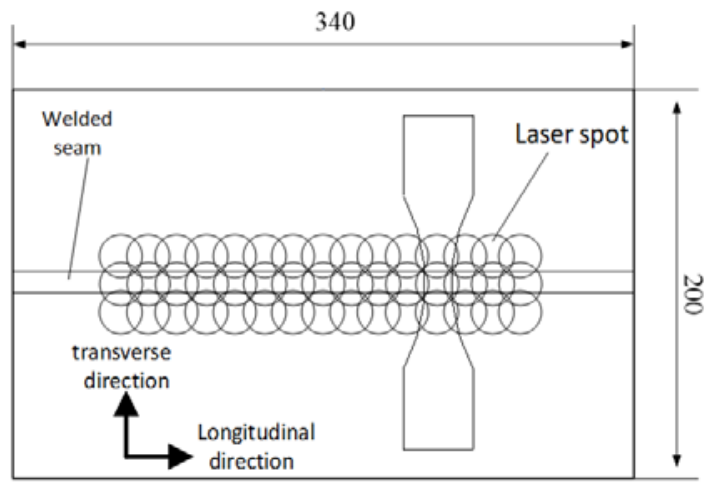

Fig.1. Sketch of LSP on laser welded plate

\section{Distribution of surface residual stresses}

Surface residual stresses were measured by XRD method on unpeened welded joints and single-side peened welded joints. X-ray beam size was diameter of $1 \mathrm{~mm}$, and angle $\psi$ were $0^{\circ}, 25^{\circ}$, $35^{\circ}, 45^{\circ}$. Distance of measuring positions from welded seam center were $0 \mathrm{~mm}, 0.5 \mathrm{~mm}, 1.5 \mathrm{~mm}$, $4 \mathrm{~mm}, 8 \mathrm{~mm}$, and three different positions were measured each distance. The results of mean residual stresses were plotted in Fig.2. Before LSP treatment, tensile stresses existed on surface of laser-welded joint, and the maximum of tensile stresses was 356MPa in longitudinal direction and about $100 \mathrm{MPa}$ in transverse direction. However, the residual stresses was totally converted to compressive state after LSP treatment. Multi-layer LSP obviously effected amplitude of compressive residual stresses on laser-welded joint surface, and values of compressive residual stresses induced by three layers LSP and five layers LSP were higher than those induced by one layer LSP. Compared with residual stresses in transverse direction, the residual stresses in longitudinal direction were lower and its affected zones were narrow. The maximum of surface residual stresses treated by three layers LSP and five layers LSP were approximate -600MPa -700MPa in longitudinal direction and approximate -300MPa -400MPa in transverse direction. 


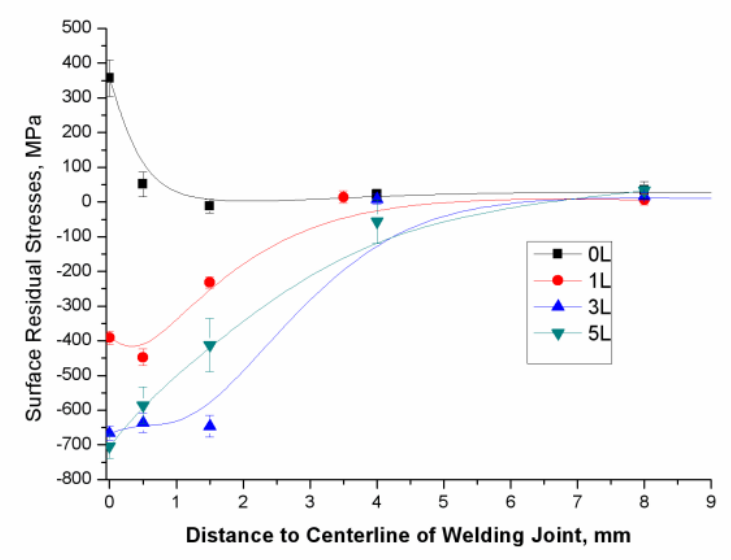

(a) L direction

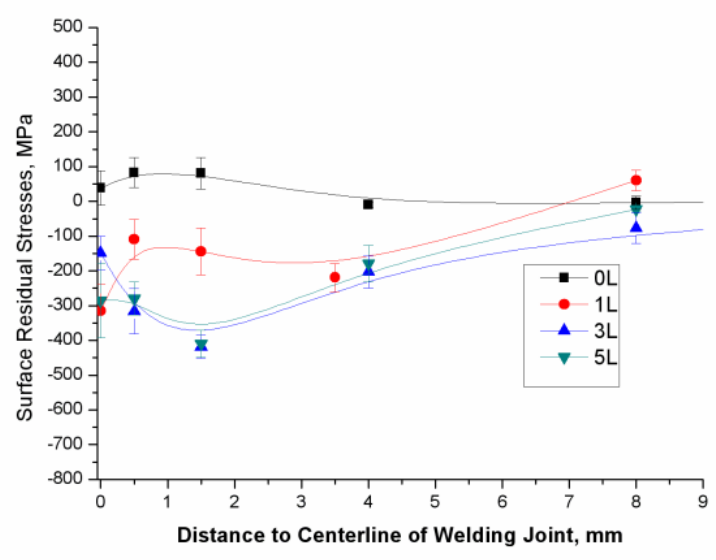

(b) $\mathrm{T}$ direction

Fig. 2. Surface residual stress distributions of welded joint before and after LSP

Moire interferometry was another method for measuring residual stresses[6]. Grating of 1200 lines/mm was pasted on laser welded joints treated by LSP, subsequently a hole was drilled with diameter of $1 \mathrm{~mm}$ and depth of $0.5 \mathrm{~mm}$. The interference fringes and residual stress results of longitudinal direction and transverse direction were shown in Fig.3 and table 2. All results of residual stresses measured by moire interferometry well matched to those of XRD method.

Table.2. Residual stresses measured by moire interferometry

\begin{tabular}{|c|c|c|c|}
\hline & 1 layer LSP & 3 layers LSP & 5 layers LSP \\
\hline $\mathrm{T}$ direction & $-208.2 \mathrm{MPa}$ & $-255.9 \mathrm{MPa}$ & -331.9MPa \\
\hline L direction & $-500.4 \mathrm{MPa}$ & $-621.7 \mathrm{MPa}$ & $-731.1 \mathrm{MPa}$ \\
\hline & 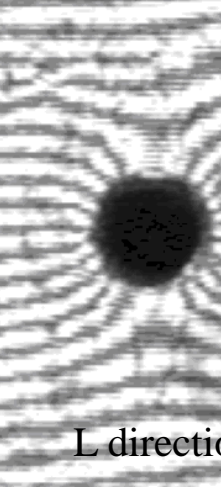 & 1 & $\frac{1}{1}$ \\
\hline
\end{tabular}

Fig.3. Interference fringe of residual stress measurement by moire interferometry

These compressive residual stresses validate plastic deformation induced by shock wave during LSP process. The compressive residual stresses enhance with increasing LSP layer because of more intense plastic deformation, but the increase of compressive residual stresses become slowly for saturated plastic strain caused by excessive shock wave load. Due to laser-spot motion paths during LSP process, the laser-welded plate maybe get a transverse distortion which lead to a relaxation of compressive residual stresses, to cause compressive residual stresses in transverse direction lower than those in longitudinal direction. In addition, excessive LSP layers are not recommended to thin plate $2.5 \mathrm{~mm}$ in this experiment, because of high amplitude of balancing tensile residual stresses in interior materials and high degree of cold work in surface LSP case[7]. Therefore, considering residual stress level and its stability, three layer LSP were performed on fatigue test specimens. Compressive residual stresses in laser welded joints can reduce stress intensity factor to limit propagation rate of fatigue crack[8].

\section{Fatigue property of Laser welded joints}

The conditions of fatigue tests were stress rate of 0.06 , maximum load of $750 \mathrm{MPa}$ and frequency of $15 \mathrm{~Hz}$. The results of fatigue tests are shown in Fig.4. The unpeened specimens were marked by 
symbol A. The specimens of three-layers LSP on upside were marked by symbol B. The specimens of three-layers LSP on both side were marked by symbol C. Each fatigue data of Specimen B and Specimen $\mathrm{C}$ was greater than any fatigue data of Specimen A. The mean fatigue life of specimen A, specimen B and specimen C were 5857cycles, 9031cycles and 9319 cycles respectively. Comparison to unpeened specimens, fatigue life of laser shocked specimens increased by $50 \%$. The effect of LSP on laser welded joints is validated from fatigue data.

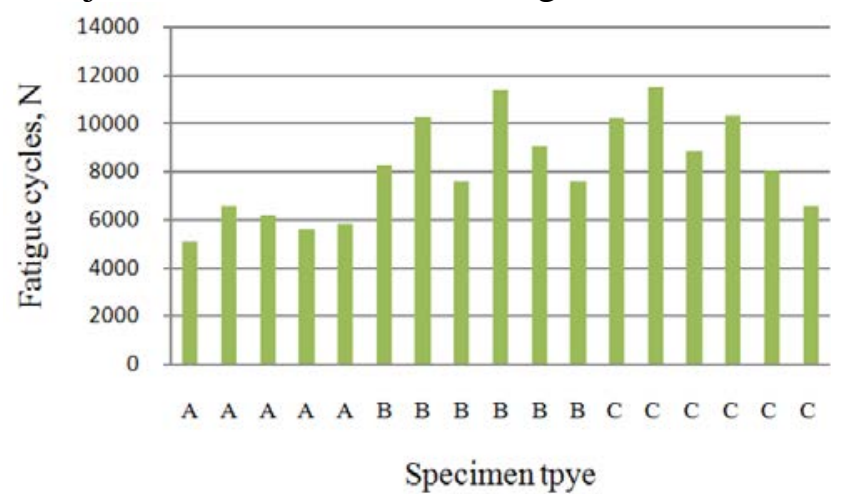

Fig.4. Fatigue life data of laser welded joints

In order to further study strengthening mechanism of LSP on laser welded joints, the cross-section of laser welded joint and fracture of fatigue test specimens were observed by means of optics and SEM. Fatigue cracks of all the specimen A initiated on upside of welded joints, and this can be explained by presence of undercut (shown in Fig.5a and Fig.5b), which located at boundary of welded seam. During fatigue test process, stress concentration which caused by undercut increased local fatigue load and accelerated formation of fatigue crack.unfortunately, these undercuts hardly can be avoided via adjusting parameters of laser welding. Crack initiation of all the specimen B occurred on underside of welded joints (shown in Fig.5c) where were not treated by LSP, because LSP strengthening layer on specimen B protected upside surface and compelled fatigue cracks to initiate at other areas. The compressive residual stresses that induced by LSP were most important factor for improving fatigue life of specimen $\mathrm{B}$, weakening effect of stress concentration at undercut. Crack initiation of specimen $C$ occurred on both side of welded joints (shown in Fig.5d) for dual side compressive residual stress fields, but mean fatigue life of specimen C were not obvious higher than that of specimen B.
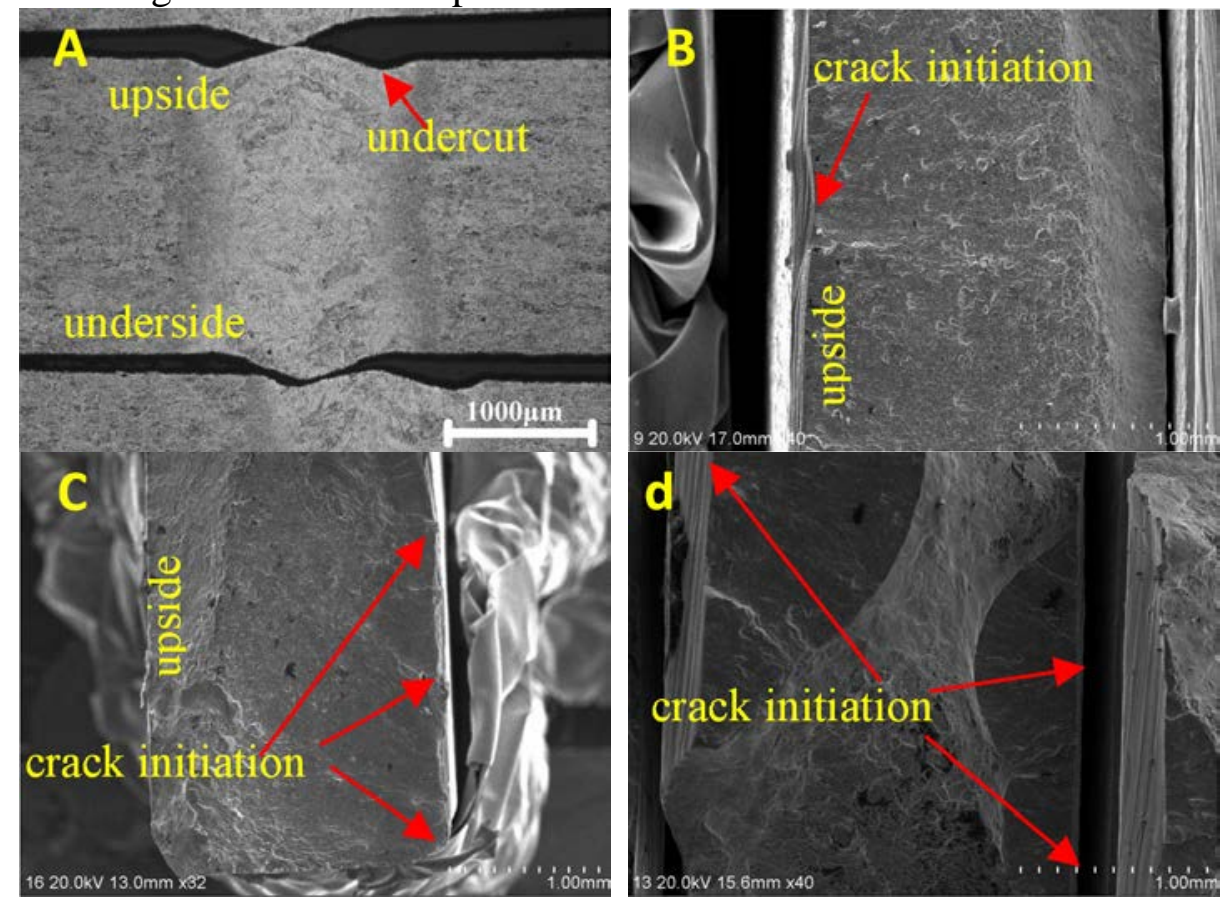

Fig.5. fatigue fracture of laser welded joints 


\section{Conclusion}

The surface stress state of laser welded joint transferred from tension to compression, and compressive residual stresses in longitudinal direction were higher than those in transverse direction. The fatigue life of laser welded joints were obviously improved by three-layers LSP treatment of single side or dual side. Imparted compressive residual stresses effected on crack initiation greater than crack propagation.

\section{References}

[1] Kerong Zhang, Jianxun Zhang. High gradient residual stresses during laser deep penetration welding of titanium alloy [J]. TRANSACTIONS OF THE CH INAWELDING INSTITUTION. 2010, 31(3) 37-40.

[2] Jing Yang, Donghai Cheng, Jihua Huang, Hua Zhang, Xingke Zhao, Heping Guo. Microstructure and Mechanical Properties of Ti-6Al-4V Joints by Laser Beam Welding [J]. Rare Metal Materials and Engineering, 2009, 38(2) 259-262.

[3] Xiaodong He, Jianxun Zhang, Yi Pe, Shuili Gong. Effects of heat input on laser welding residual stress and distribution of TC4 Titanium alloy [J]. Rare Metal Materials and Engineering, 2007, 36(5) 774-777.

[4] Y. Sano, T. Adachi, K. Akita, I. Atenberger. Enhancement of surface property by low-energy laser peening without protective coating [J]. Key Engineering Materials, 2007, Vol 345-346: 1589-1592.

[5] Lloyd. A. Hackel, C. Brent. Dane, Jon. Rankin, Fritz Harris. Laser peening technology and remote processing of pressure vessels [J]. 2005 ASME Pressure and Piping Division Conference July 17-21, 2005, Denver, Colorado, USA:197-202.

[6] Jidong Kang. Experimental studies on J-dominance in hete-rogeneous welded joints by moire interferometry [J]. Transactions of Nanjing University of Aeronautics \& Astronautics, 1997, 14(2) 186-189.

[7] Charles S. Montross, Tao Wei, Lin Ye, Graham Clark, Yiu-Wing Mai. Laser shock processing and its effects on microstructure and properties of metal alloy: a review [J]. International Journal of Fatigue, 24(2002) 1021-1036.

[8] C. Rubio-Gonzalez, J.L. Ocana, G. Gomez-Rosas. Effect of laser shock processing on fatigue crack growth and fracture toughness of 6061-T6 aluminum alloy [J]. Materials Science and Engineering A, 386(2004):291-295. 